THE ANNALS OF "DUNAREA DE JOS" UNIVERSITY OF GALATI

FASCICLE XV ISSN - 1454 - 9832 - Vol. 2/2019

Article DOI: https://doi.org/10.35219/efms.2019.2.08

\title{
THE ROLE OF ACTIVE TOURISM FORMS ON ADOLESCENTS' SOCIALIZATION
}

\author{
Mihail Onoi, Vasile Mindrigan, Natalia Nastas \\ State University of Physical Education and Sport, Chisinau, Republic of Moldova \\ e-mail: turspor@gmail.com
}

\begin{abstract}
The current global (environmental, social, national, political, moral) issues have an impact on the development of society, civilization, culture, while a particularly important object of the impact of these issues is the young generation, especially adolescents.

Active tourism is a combination of phenomena and relationships, occurring on the journey, characterized by an active way of travelling on a route, with energy expenditure, made for recreational or sports purposes. In active tourism, there are several types and forms (walking tours, hiking, excursions etc.).

The tasks of active tourism can be formulated as follows: socialization and integration of the younger generation, physical training, acquiring technical procedures, tourism exercises and other sports samples (technical training), the acquisition of sport-tourism tactics, the formation of motor skills and abilities, education and the development of intellectual, moral, social and voluntary qualities.
\end{abstract}

Keywords: socialization process, adolescents, tourism activities, active tourism forms

\section{Introduction}

At present, the society in which we live is characterized by a high degree of socio-psychological and political instability. In his conception [2, p. 265], in adolescence there are spectacular changes in the affectivity plan, which made the authors consider this period as "the age of storm and stress" or "emotional vivacity".

The analysis of the situation in the adolescent environment suggests that in recent years, against the background of the crisis phenomena of the Moldovan society, there has been a significant increase in the various forms of antisocial behavior of adolescents.

ЛинчевскийЕ., (2012)reveals that a teenager, being involved in various types of socially meaningful activities, expands the sphere of communication, the possibilities of assimilation of social values, forms the moral qualities of the individual.

The practice of various forms of active tourism fits perfectly in solving this complex problem of socializing adolescents.

The various forms of active tourism [6, p. 48] aim at making profits, achieving social and cultural goals, such as creating equal opportunities for people's access to cultural values, preserving a unique cultural space and supporting the diversity of cultural life, interregional cooperation.

The research hypothesis. It is assumed that the form of active tourism is the socialization factor for adolescents, but currently with a small share in their activities.

The aim of the research was to establish the concept of teaching staff in general education on the role of the various forms of active tourism in order to socialize adolescents.
Objectives of the research:

1. Analysis of the specialized literature on the specificity of the adolescent socialization process in active tourism.

2. Determining the level of socialization of adolescents in practicing various forms of active tourism, in the opinion of specialists in the field.

The subjects of the research were 181 teachers from rural and urban areas of the Republic of Moldova.

\section{Materials and methods}

The following research methods were used to achieve the objectives: analysis of the scientificmethodical literature; pedagogical observation and questionnaire survey.

Researching the concepts of specialists on practicing various forms of active tourism in order to socialize adolescents was based on a questionnaire applied to teachers, which aimed to determine the level of socialization of adolescents by practicing forms of active tourism.

The survey questionnaire was carried out on a sample of 181 teachers from different districts of the Republic of Moldova from rural and urban areas.

Please note that for some questions in the questionnaire, the respondents opted for one or more of the answers variants (10 questions with 28 variants of answer).

\section{Results and Discussions}

Following the views expressed by the 181 teachers aged 23-70 from general education institutions, 58 of whom from the urban area and 123 from the rural area participating in this research, pointed out that tourism 


\section{THE ANNALS OF "DUNAREA DE JOS" UNIVERSITY OF GALATI \\ FASCICLE XV ISSN - 1454 - 9832 - Vol. 2/2019}

activities, especially the forms of active tourism, can influence the socialization of adolescents. In support of these assertions, teachers' answers come. Thus: to the question of whether teachers influence the adolescent socialization process, $80,2 \%$ of teachers consider teachers to influence the socialization of adolescents (Figure 1), which shows us that the teacher has the influence on teenagers when it comes to socializing them. However, $13,6 \%$ believe that the teacher partly influences this process.

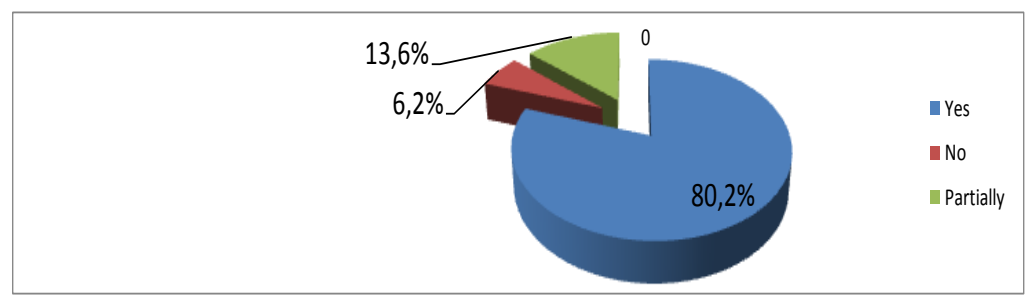

Figure 1. Influence of Teachers on the Adolescent Socialization Process

School, the space of the interaction of its actors, pupils (teenagers) and teachers alike, have, in our opinion, a decisive role in defining the identity of each member of society. The way in which the school sees and implements the principles of inter-human cohabitation, puts its mark on adolescent personality formation.

Formal education, that is, in public or private school institutions, is the most powerful way consciously and consistently used to bring the group to influence a person. The teacher is delegated to instill those elements of culture necessary to be a satisfactory member of the group. Like parents, teachers are invested with a public responsibility [5].

The analysis of this subject has allowed us to establish that socialization is a process that includes itself [3, p. 38]:
- adapting the person to the real world;

- internalizing values and norms, knowing the elements of culture;

- the transmission of personal values in the process of activity in the social environment.

In this context, we asked teachers to provide 3 examples of activities involving the socialization process. Thus, the respondents offered more answers but the most eloquent were extra-curricular activities with 17,3\%, excursions by $14,8 \%$ and tourist marches by $12,3 \%$ (Figure 2). We can deduce that, in the opinion of the respondents, tourism activities are the ones that involve the socialization process.

\section{Figure 2. Examples of activities involving the socialization process}

Tourist activities are activities in which, through the different forms of tourism as the main and characteristic means, man acts upon him, the object of action being his own body. The main purpose for which these activities are practiced is to optimize the process of both physical and implicit development of the human psyche. Practiseing various forms of tourism on a regular basis are activities that contribute to the improvement of biological characteristics, the formation of character and moral profile, cultivate respect for the values of society, give adolescents the opportunity to socialize. This caused us to ask the respondents whether tourism activities can become a socializing agent, and the majority of $91,4 \%$ are convinced that tourism activities may well become a socializing agent for adolescents and only $8,6 \%$ consider that they would partially become. 


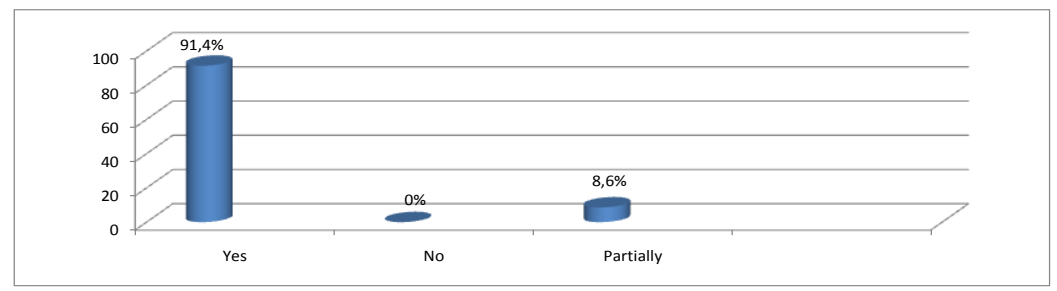

Figure 3. Tourist activities - socializing agent for teenagers

Based on the fact that the respondents responded $17,3 \%$ of the extra school activities involved in the socialization process, the interviewees were asked if they had such activities with the adolescent involvement this year Figure 4).

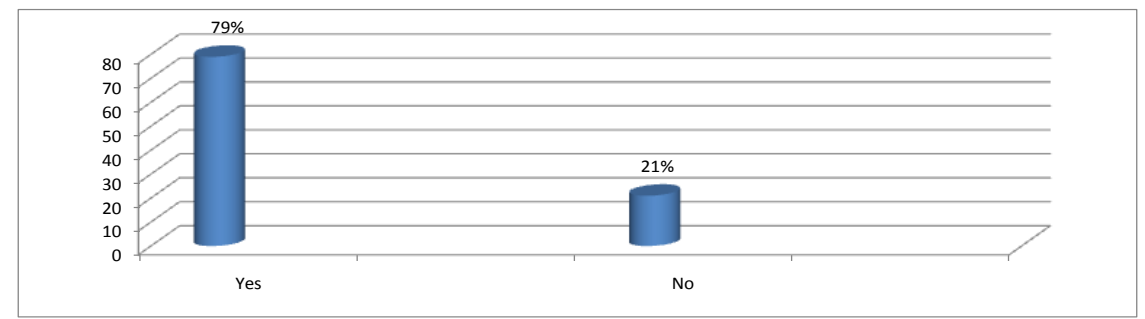

Figure 4. Developing extracurricular activities with adolescent involvement this year

From Figure 4 we can see that most of the respondents, i.e. $79 \%$ or 143 of the respondents, mentioned that this year they did extracurricular activities with adolescent involvement and only 38 did not. This shows that extracurricular activities contribute to forming the teenager's personality. These are important and useful.

Through the variety of socialization opportunities present in the student class, school is one of the most significant socializing agents. But these resources are used and capitalized incompletely and unilaterally, especially in the direction of integrating and conforming pupils (adolescents) to the normative system of school culture [4].

Analyzing the opinions of the specialists we decided to ask the teachers, which should be the main function of school (Figure 5), and the majority of $48,1 \%$ thought that the main function should be knowledge transfer, $29,6 \%$ socialization, and $22,3 \%$ adolescent training.

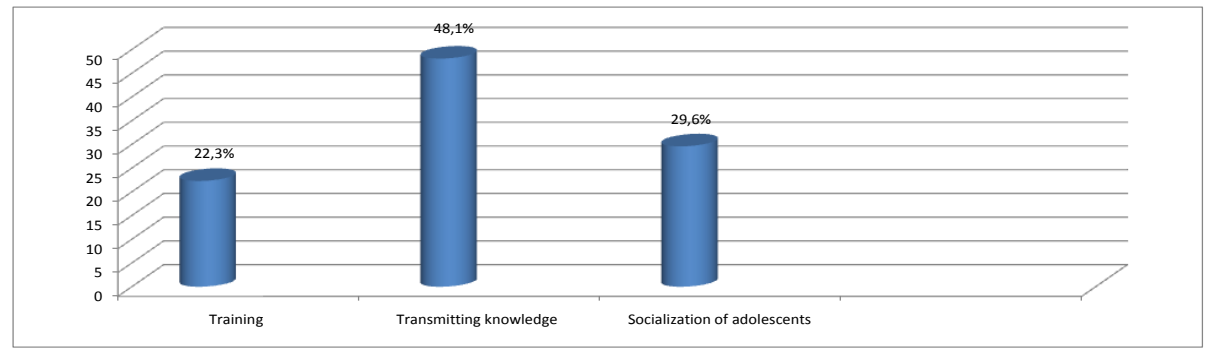

Figure 5. The main function of the school 


\section{THE ANNALS OF "DUNAREA DE JOS" UNIVERSITY OF GALATI \\ FASCICLE XV ISSN - 1454 - 9832 - Vol. 2/2019}

As it can be seen (Figure 5), the opinion of the questioned teachers was concretized in favor of the transfer of knowledge $48,1 \%$, those who dared to socialize the adolescents constituted $29,6 \%$, and for the vocational training $22,3 \%$. From the answers we can deduce that school is another factor whose influence in this process cannot be questioned. It is an essential step in acquiring the skills of integration and cohabitation with others within a society. The primary task of the school from this point of view is not only to teach pupils (teenagers) different abilities or to provide them with a wealth of information and knowledge but, above all, to prepare them for life in society, to form them in the sense of assimilating the values and norms specific to the social world in which they were born and are to develop their adult life. The experience of socializing through the school forces the adolescent to confront unusual situations that cannot be met in family life [1].

Considering that the school has an important role in the socialization process, we asked the respondents about the degree of socialization of adolescents in the institutions they represent on a scale of 1-10 (Figure 6).

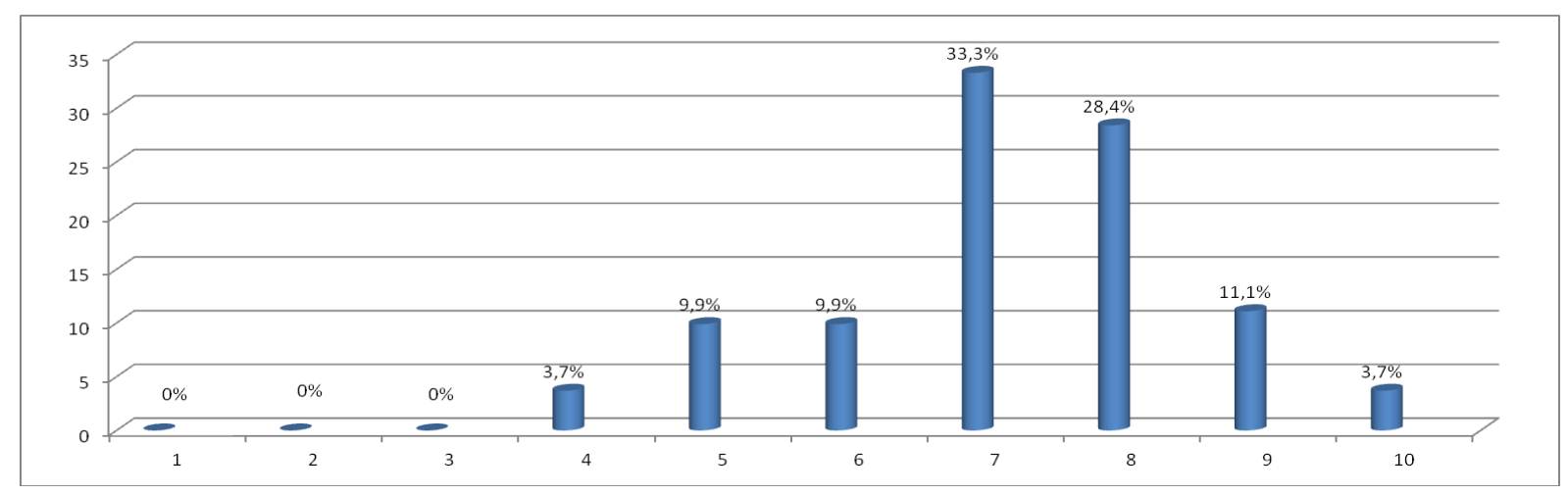

Figure 6. The degree of socialization of adolescents in school institutions on a scale of 1-10

The majority of teachers, i.e. $61,7 \%$, consider that the degree of socialization of adolescents in the institutions they represent is $7-8,23,5 \%$ mentioned a grade between $4-6$ and $14,8 \%$ believe that within the institutions that they represent the degree of socialization of their adolescents is located between 9-10. From Figure 6 , we can see that the degree of socialization within the school is not so weak, which confirms the authors hypothesis, which mentions that school is a key element in forming the teenager's personality.

The whole of people who interact with us in one way or another, throughout our lives, make up our social environment. Today people interact with each other much more intensively than in the past, thanks to books, newspapers, films, TV programs, mobile telephony, the Internet, etc. But all of this is mostly done in a virtual environment where people can lie, hide emotions, etc. That is why we considered it necessary to ask the respondents whether in the present society adolescents need socialization in various forms (Figure 7). Thus, $95,1 \%$ of respondents mention that adolescents need socialization in various forms in the current society, and $4,9 \%$ believe it partly.

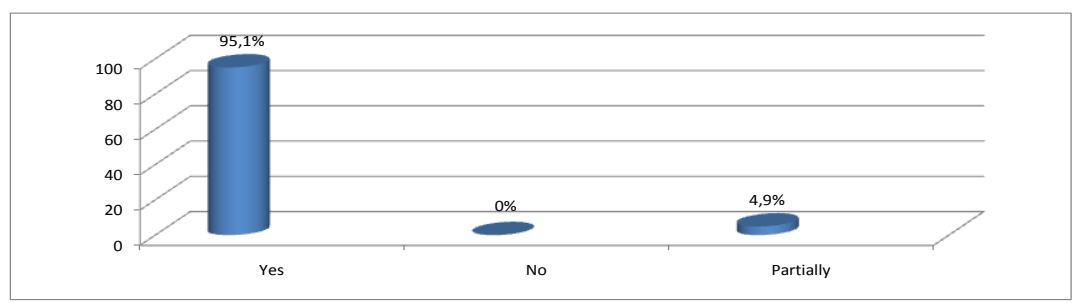

Figure 7. The need to socialize adolescents in various forms in today's society

With the evolution of society, from moral principles to the subjugation of man by money, today's adolescents have more free time, fewer responsibilities, and less watch than those in past generations, spending time in malls, fast food, in parks or elsewhere.

This led us to ask teachers how they think their teenagers are doing their free time (Figure 8). 


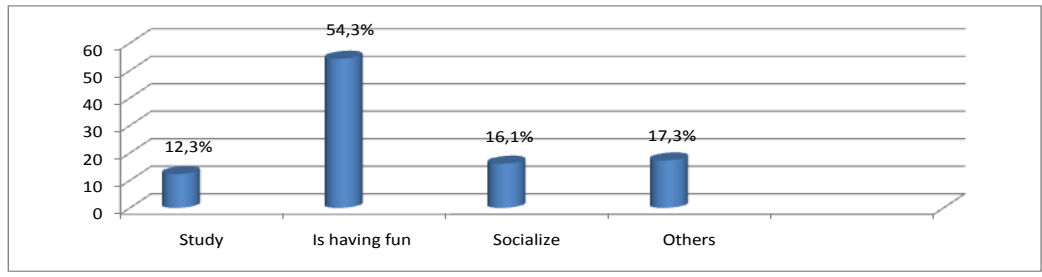

Figure 8. Leisure time development by teenagers

The values obtained (Figure 8) confirm that a large part of 54,3\% of adolescents have fun, which confirms the theoreticians' opinion, and only $16,1 \%$ socialize, which makes them difficult in some situations in life.

A high-tech school is a school where a strong bond between teachers and parents is promoted, sustained and developed. It is a partnership in which, never forget, the core is the student (adolescent). The communication, teenage information sharing must come from both directions, studies showing that a good parent-teacher relationship correlates with the teenager's good school performance. That is why in question 9 we considered it necessary to ask the respondents about whether socialization is important in establishing a good parentteenager-teacher relationship (Figure 9).

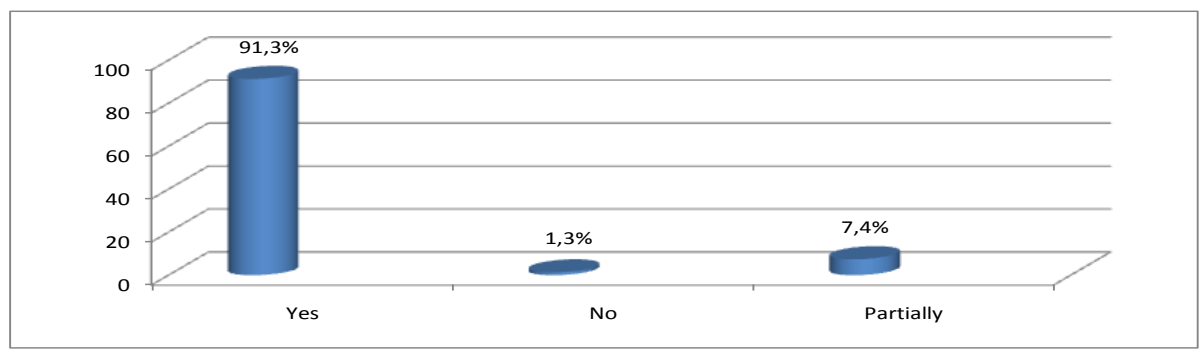

Figure 9. The Importance of Socialization in Establishing the Parent-Teenager -Teacher Relationship

In this question (Figure 9), 91,3\% answered in full and affirmative that socialization is of great importance in establishing the parent-teenager-teacher relationship, $1,3 \%$ considers it important and 7,4\% believe it is partly important. The data we get suggests that the communication between the parent and the teacher (head teacher) must be constant, involve all available means and address both the negative aspects, but especially the positive aspects.

Considering that the second question respondents saw in tourism activities an essential socializing agent of adolescents, we asked them if they opted for the organization of formsof active tourism (excursions, tourist marches, actions and tourist meetings etc.) in the institutions where they come from (Figure 10). 


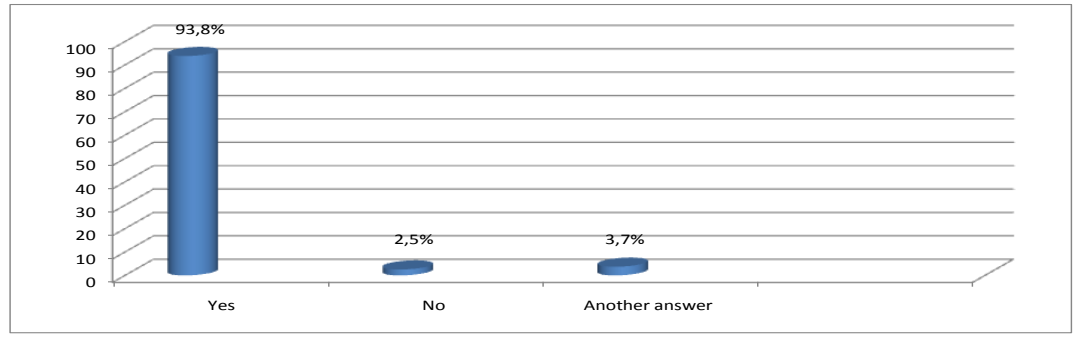

Figure 10. The need to organize forms of active tourism in school institutions

The vast majority of respondents (Figure 10) are of the opinion that forms of active tourism must be organized in school institutions, 2,5\% think no, but 3,7 another answer including:

- to introduce optional courses (school tourism departments);

- can be organized, but periodically and thematically;

- just according to the curriculum;

- are welcome for teenagers.

\section{Conclusion}

We can mention that, by analyzing the obtained data, $80,2 \%$ of the teachers influence the adolescent socialization process. At the same time, extracurricular and tourist activities are those, which in the respondents' opinion imply the socialization process, which is expressed by $62,9 \%$ of the teachers. Most $91,4 \%$ consider that tourism (forms of active tourism) should become a socializing agent, and adolescents at present need $95,1 \%$ socialization.

By generalizing the opinions of the specialists in the field of adolescent socialization in the opinion of the teaching staff of the general education of the Republic of Moldova, it is noticed that the majority are aware of the importance of socialization in forming the adolescent personality in the present society. For this, the latter should be more involved in extracurricular and tourist activities. However, the use of forms of active tourism is welcome, but would require the introduction of optional courses (tourism hours in schools); periodically organizing and according to a theme of these activities and only according to the curriculum.

\section{References:}

1. Anastasiu, I. (2011) The family and the school look like - agents of socialization, Bucharest: ASEM

2. Debesse, M., Hall, S., apud Cretu, T. (2009) Psychology of the ages, Iasi: Polirom Publishing House, p. 352.
3. Paladi, O. (2013) Psychological and pedagogical approaches to the socialization process. In: UniversulPedagogicReviewNo. 2 (38), pp. 33-41.

4. Rîşnoveanu, A. (2010) School - socializing agent. Theories, peculiarities, practices. University Publishing House.

5. Wilson, (1971), https://anatolbasarab.ro/scoalaspatiu-cultural-al-socializarii/- accessed 20.02.2019).

6. Lazovskiy, VF, Maymula, G.V. (2014) Perspectives develops the tourist complex. Проблемы управления развитием организачии $и$ опыт подготовки менеджеров. Сборник научных трудов. Krasnodar, c. 48-51.

7. Линчевский, Э.Э. (2012) Психологический климат туристской группь. 3rd Edition, HandbookandDissolution.Санкт-Петербург. 160 c. 